\title{
Anaemia requiring red blood cell transfusion is associated with unfavourable 90-day survival in surgical patients with sepsis
}

\author{
Katalin Kristof ${ }^{1 \dagger}$, Benedikt Büttner ${ }^{1 \dagger}$, Anna Grimm ${ }^{1}$, Caspar Mewes ${ }^{1}$, Bastian Schmack ${ }^{2}$, Aron Frederik Popov ${ }^{3}$, \\ Michael Ghadimi ${ }^{4}$, Tim Beissbarth ${ }^{5}$, José Hinz ${ }^{1}$, Ingo Bergmann ${ }^{1+}$ and Ashham Mansur ${ }^{1{ }^{*+}}$ (D)
}

\begin{abstract}
Objective: The mortality associated with sepsis remains unacceptably high, despite modern high-quality intensive care. Based on the results from previous studies, anaemia and its management in patients with sepsis appear to impact outcomes; however, the transfusion policy is still being debated, and the ideal approach may be extremely specific to the individual. This study aimed to investigate the long-term impact of anaemia requiring red blood cell (RBC) transfusion on mortality and disease severity in patients with sepsis. We studied a general surgical intensive care unit (ICU) population, excluding cardiac surgery patients. 435 patients were enrolled in this observational study between 2012 and 2016.
\end{abstract}

Results: Patients who received RBC transfusion between 28 days before and 28 days after the development of sepsis $(n=302)$ exhibited a significantly higher 90 -day mortality rate (34.1\% vs $19.6 \% ; P=0.004$, Kaplan-Meier analysis). This association remained significant after adjusting for confounders in the multivariate Cox regression analysis (hazard ratio $1.68 ; 95 \%$ confidence interval $1.03-2.73 ; \mathrm{P}=0.035$ ). Patients who received transfusions also showed significantly higher morbidity scores, such as SOFA scores, and ICU lengths of stay compared to patients without transfusions $(n=133)$. Our results indicate that anaemia and RBC transfusion are associated with unfavourable outcomes in patients with sepsis.

Keywords: Sepsis, Red blood cell transfusion, Surgical ICU, Mortality, Organ dysfunction, Survival, Organ support, Morbidity

\section{Introduction}

Despite the significant improvements in critical care medicine and intensive research in the field, sepsis and related organ dysfunction remain major causes of mortality, even in the developed world [1]. The pathophysiology of organ failure in patients with life-threatening infections is diverse, including direct cytotoxicity of bacterial toxins, collateral damage through inflammation, and tissue ischemia [2-4]. Since the dysregulation

\footnotetext{
*Correspondence: ashham.mansur@med.uni-goettingen.de

${ }^{\dagger}$ Katalin Kristof, Benedikt Büttner, Ingo Bergmann and Ashham Mansur contributed equally to this work

${ }^{1}$ Department of Anesthesiology, University Medical Center, Georg August University, Goettingen, Germany

Full list of author information is available at the end of the article
}

of the microcirculation is common in patients with sepsis [4-7], inadequate perfusion of organs may occur, even if cardiac output and systemic blood pressure are formally in the normal range. Given the reduced density of functioning capillaries in patients with sepsis, theoretical considerations suggest that this patient group might be more sensitive to anaemia, which is indeed very common in septic patients. Anaemia is related to haemolysis, impaired blood clotting with a bleeding tendency and decreased erythrocyte growth $[8,9]$. Under these circumstances, the intended benefit of RBC transfusion is to increase oxygen delivery to starving organs; however, the correction of anaemia in this patient group is by far a more complex question in the clinical setting than at the theoretical level [10-14]. Although life-threatening 
transfusion-related adverse reactions are relatively rare from the classical perspective [15], the administration of blood products represents an allogenic transplantation, which raises several questions. Regarding erythrocytes, the most problematic aspects include transfusion-related immunomodulation $[16,17]$, impaired rheological properties and reduced oxygen release from stored RBCs [1820]. Additionally, microparticles originating from stored RBCs exert detrimental effects on homeostasis, including the promotion of coagulation and immunomodulation [21].

Based on two studies revealing the lack of additional benefits of a liberal transfusion regimen from a statistical perspective, recent guidelines recommend a transfusion threshold of $7 \mathrm{~g} / \mathrm{dL}$ for septic patients without further risk factors, such as myocardial ischemia, severe hypoxemia or acute blood loss [13, 22, 23]. However, a different study concluded that septic patients who received RBC transfusions exhibited reduced 7-day, 28-day and in-hospital mortality after adjustment in the multivariate analysis [24]. These data indicate the heterogeneity of patient groups with sepsis. Indeed, a recent large metaanalysis confirmed that "the data on RBC transfusions in patients with sepsis are sparse, and the high heterogeneity between studies prevents from drawing any definitive conclusions" [25]. We focused on a general surgical ICU population with sepsis, excluding cardiac surgery patients due to their particularly high bleeding risk, to investigate the possible associations between anaemia, blood transfusions and outcomes in a homogeneous patient group. Unlike most previous studies, we chose a long (90-day) observation period for mortality as the primary outcome. Because of the immunomodulatory effects of stored allogenic erythrocytes, RBC transfusions as early as 28 days before the beginning of sepsis were considered. The observation period for transfusion was then continued for an additional 28 days after enrolment.

\section{Main text \\ Materials and methods \\ Study population}

Surgical patients with sepsis were recruited through the GENOSEP database of the Department of Anesthesiology at the University Medical Center, Goettingen, Germany. This database comprises a prospectively collected cohort of ICU patients with sepsis. All patients treated at the surgical ICUs of the University Medical Center Goettingen between March 2012 and March 2016 were screened for sepsis on a daily basis as described previously [26-28]. Sepsis was defined according to the 2012 standards as a microbiologically or clinically obvious infection with the presence of two or more systemic inflammatory response syndrome (SIRS) criteria, because the new 'sepsis 3' definition was not available at the beginning of the study [29]. The exclusion criteria were an age less than 18 years, pregnancy, therapy with immunosuppressive drugs or chemotherapy, human immunodeficiency virus (HIV) infection, chronic heart failure classified as New York Heart Association (NYHA) stage IV, or acute myocardial infarction. Moribund patients were also excluded. No patients enrolled in this study were lost to follow-up. Cardiac surgery patients were not enrolled in this study because of their disproportionally high risk of bleeding.

\section{Collection of data}

On day 1 (beginning of sepsis and enrolment in the study), the following data were collected: age, gender, pre-existing medical conditions and medications, focus of infection, and SOFA and Acute Physiology and Chronic Health Evaluation (APACHE II) scores. The patients were then followed for 28 days. Over the course of the ICU stay, the following data were collected: vital parameters, routine blood tests, including a blood gas analysis, SOFA score, organ support (renal replacement therapy, mechanical ventilation, and vasopressors), antibiotics used and culture results. Days without organ support were the number of days in the 28-day observation period a patient did not require organ support therapy. We obtained data on the transfusion of erythrocytes in the timeframe of 28 days before and 28 days after the beginning of sepsis. On day 90 , the status of our enrolled patients was evaluated.

\section{Data analysis}

We used Statistica Software (Version 13, StatSoft, Tulsa, Oklahoma, USA) to analyse the data. The significance of the categorical variables was calculated using Pearson's Chi Square test. Continuous variables were compared using the Mann-Whitney U test. The mortality risk analysis was performed by comparing time-to-event data using the log-rank test. We performed a multivariate Cox regression analysis to exclude the effects of potential confounders and covariates that varied at baseline (e.g., comorbidities) on survival. $P$ values $\leq 0.05$ were considered significant. In tables, continuous variables are presented as means \pm standard deviations and categorical variables are presented as absolute numbers or percentages.

\section{Results}

\section{Baseline characteristics at the time of enrolment}

435 Caucasian patients with sepsis who were admitted to the surgical ICUs of the University Medical Center Goettingen were enrolled in this study. Patients in the transfusion group $(n=302)$ exhibited significantly higher 
baseline SOFA scores $(9.5 \pm 3.8$ vs. $7.5 \pm 3.0 ; \mathrm{P}<0.001)$, APACHE II scores $(21.6 \pm 6.6$ vs. $19.0 \pm 6.1 ; \mathrm{P}<0.001)$ and an increased prevalence of septic shock on day 1 (69\% vs. $51 \% ; \mathrm{P}<0.001)$ compared with patients in the non-transfusion group $(\mathrm{n}=133)$. Patients who received an $\mathrm{RBC}$ transfusion required significantly more vasopressors $(69 \%$ vs. $51 \%$; $\mathrm{P}<0.001)$ and renal replacement therapy ( $9 \%$ vs. $2 \% ; \mathrm{P}=0.004)$ at baseline. The transfusion group more frequently had a previous medical history of malignant tumours than the transfusion-free group (23\% vs. $12 \% ; \mathrm{P}=0.007$ ), whereas a previous history of stroke was rarer in these patients ( $4 \%$ vs. $10 \% ; \mathrm{P}=0.027$ ). No differences in age, gender and comorbidities other than those mentioned above were identified. Although a pulmonary focus followed by an abdominal focus was the most frequent site of infection, patients who received an $\mathrm{RBC}$ transfusion experienced a significantly greater incidence of an abdominal focus as site of infection than patients in the transfusion-free group $(32 \%$ vs. $16 \%$; $\mathrm{P}=0.046)$. All data on baseline characteristics are shown in Table 1.

\section{Mortality analysis}

Patients who received RBC transfusion showed a significantly higher 90 -day mortality risk than patients without an RBC transfusion, in the Kaplan-Meier survival analysis $(34.1 \%$ vs. $19.6 \%$; $P=0.004$; Fig. 1$)$. A higher mortality risk among patients in the RBC group was also observed at the 28-day time point, although this difference was not significant (20.2\% vs. $13.5 \%$; $=0.1$; Table 2$)$.

\section{Multivariate analysis}

A multivariate Cox regression analysis was performed to adjust for possible effects of different baseline

Table 1 Baseline characteristics of surgical patients with sepsis

\begin{tabular}{|c|c|c|c|c|}
\hline Parameter & All surgical patients $(n=435)$ & $\begin{array}{l}\text { Patients who received } \\
\text { an } \mathrm{RBC} \text { transfusion } \\
(\mathrm{n}=302)\end{array}$ & $\begin{array}{l}\text { Patients without an RBC } \\
\text { transfusion }(n=133)\end{array}$ & $P$ value \\
\hline Age (years) & $62 \pm 15$ & $63 \pm 15$ & $61 \pm 15$ & 0.25 \\
\hline Gender (male \%) & 64 & 63 & 65 & 0.66 \\
\hline $\mathrm{BMI}\left(\mathrm{kg} / \mathrm{m}^{2}\right)$ & $27 \pm 6$ & $27 \pm 5$ & $28 \pm 7$ & 0.93 \\
\hline Septic shock (day 1) [\%] & 63 & 69 & 51 & 0.0004 \\
\hline SOFA score (day 1) & $8.9 \pm 3.7$ & $9.5 \pm 3.8$ & $7.5 \pm 3.0$ & $<0.001$ \\
\hline APACHE II score (day 1) & $20.8 \pm 6.5(n=430)$ & $21.6 \pm 6.6(n=300)$ & $19.0 \pm 6.1(n=130)$ & 0.0002 \\
\hline \multicolumn{5}{|l|}{ Comorbidities (\%) } \\
\hline Arterial hypertension & 52 & 50 & 56 & 0.22 \\
\hline Previous myocardial infarction & 5 & 6 & 2 & 0.12 \\
\hline COPD & 12 & 14 & 8 & 0.12 \\
\hline Kidney disease & 9 & 10 & 6 & 0.22 \\
\hline Diabetes mellitus (insulin-dependent) & 9 & 10 & 9 & 0.85 \\
\hline Diabetes mellitus (not insulin-dependent) & 8 & 7 & 10 & 0.31 \\
\hline Chronic liver disease & 6 & 7 & 4 & 0.24 \\
\hline Malignant tumour & 20 & 23 & 12 & 0.0072 \\
\hline Stroke & 6 & 4 & 10 & 0.0266 \\
\hline \multicolumn{5}{|l|}{ Site of infection (\%) } \\
\hline Pulmonary & 56 & 52 & 66 & 0.14 \\
\hline Abdominal & 28 & 32 & 16 & 0.0457 \\
\hline Bones or soft tissues & 4 & 5 & 2 & 0.45 \\
\hline Surgical wounds & 2 & 2 & 2 & 0.54 \\
\hline Urogenital & 2 & 2 & 3 & 0.73 \\
\hline Primary bacteraemia & 4 & 5 & 2 & 0.58 \\
\hline Other & 4 & 2 & 7 & 0.0130 \\
\hline \multicolumn{5}{|l|}{ Organ support (day 1) [\%] } \\
\hline Mechanical ventilation & 85 & 86 & 83 & 0.53 \\
\hline Vasopressors & 63 & 69 & 51 & 0.0004 \\
\hline Renal replacement therapy & 7 & 9 & 2 & 0.0042 \\
\hline Medication with statins [\%] & 20 & 22 & 16 & 0.13 \\
\hline
\end{tabular}

Italic indicates significance of $P$ values $(P<0.05)$ 


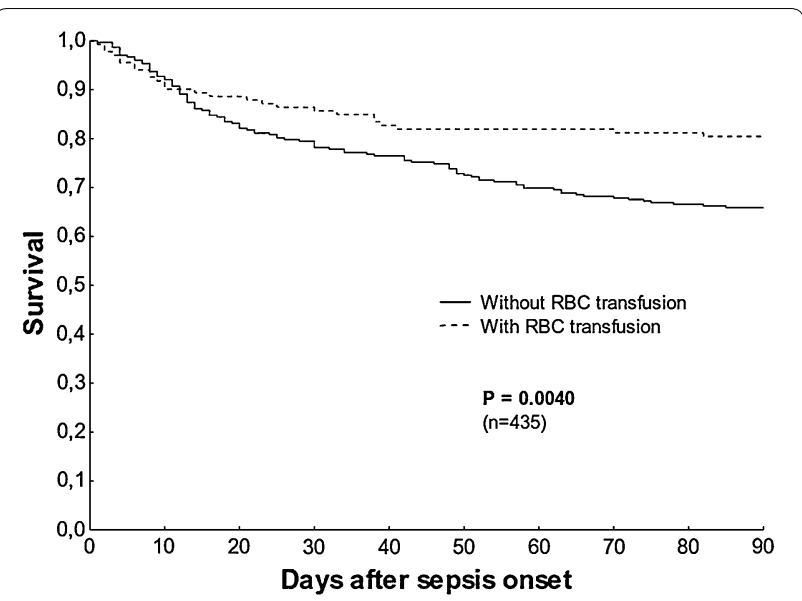

Fig. 1 Kaplan-Meier 90-day survival analysis

characteristics and potential confounders on 90-day mortality. It included RBC transfusion, potential confounders (age, gender and SOFA and APACHE II scores), and covariates that varied at baseline (septic shock, a medical history of tumours or stroke, abdominal foci and other foci as sites of infection, and vasopressors and renal replacement therapy on day 1). The transfusion of RBCs was independently associated with a higher 90-day mortality (hazard ratio (HR) 1.68; 95\% confidence interval $(\mathrm{CI}) 1.03-2.73 ; \mathrm{P}=0.035)$. Further independent risk factors included an age greater than 65 years (HR 1.59; 95\% CI 1.08-2.36; $\mathrm{P}=0.020)$ and a higher APACHE II score on day 1 (HR 1.04; 95\% CI 1.00-1.08; P =0.043). Patients with an abdominal focus exhibited a significantly better outcome (HR 0.23; 95\% CI 0.06-0.85; P=0.007). Data are presented in Additional file 1: Table S1.

\section{Disease severity}

The transfusion group showed a higher average SOFA score during their ICU stay than the group without an $\mathrm{RBC}$ transfusion $(7.1 \pm 3.4$ vs. $5.2 \pm 2.1 ; \mathrm{P}<0.001)$. Regarding the SOFA score, patients transfused with RBCs scored higher on the SOFA-Respiratory system, SOFA-Kidney, SOFA-Cardiovascular system, SOFALiver and SOFA-Coagulation subscales. The transfusion group also showed a longer average ICU length of stay ( $20 \pm 15$ vs. $12 \pm 7$ days; $\mathrm{P}<0.001)$ than the non-transfusion group.

The microbiological spectrum of pathogens isolated from cultures of the two patient groups were similar with respect to Gram-positive and Gram-negative pathogens. However, the transfusion group exhibited a significantly higher number of positive fungal cultures (62\% vs. $35 \%$; $\mathrm{P}<0.001)$. Disease severity data are illustrated in Table 2.

\section{Discussion}

In this observational study, we investigated the relationship between anaemia requiring an RBC transfusion

Table 2 Disease severity of surgical patients with sepsis

\begin{tabular}{|c|c|c|c|c|}
\hline Parameter & $\begin{array}{l}\text { All surgical patients } \\
(n=435)\end{array}$ & $\begin{array}{l}\text { Patients who received an RBC } \\
\text { transfusion }(n=302)\end{array}$ & $\begin{array}{l}\text { Patients without an RBC } \\
\text { transfusion }(n=133)\end{array}$ & $P$ value \\
\hline SOFA score & $6.5 \pm 3.2$ & $7.1 \pm 3.4$ & $5.2 \pm 2.1$ & $<0.001$ \\
\hline SOFA-respiratory system & $1.8 \pm 0.8$ & $1.9- \pm 0.8$ & $1.6 \pm 0.7$ & 0.0005 \\
\hline SOFA-kidneys & $0.6 \pm 1.0$ & $0.8 \pm 1.1$ & $0.2 \pm 0.6$ & $<0.001$ \\
\hline SOFA-cardiovascular system & $1.4 \pm 0.9$ & $1.6 \pm 0.9$ & $1.1 \pm 0.9$ & $<0.001$ \\
\hline SOFA-liver & $0.3 \pm 0.7$ & $0.4 \pm 0.7$ & $0.1 \pm 0.4$ & $<0.001$ \\
\hline SOFA-coagulation & $0.3 \pm 0.5$ & $0.3 \pm 0.6$ & $0.1 \pm 0.2$ & $<0.001$ \\
\hline SOFA-nervous system & $2.0 \pm 1.1$ & $2.0 \pm 1.1$ & $2.0 \pm 1.1$ & 0.86 \\
\hline 28-day mortality (\%) & 18 & 20.2 & 13.5 & 0.10 \\
\hline $\begin{array}{l}\text { ICU length of stay (from the beginning of sepsis } \\
\text { to discharge) }\end{array}$ & $17 \pm 13$ & $20 \pm 15$ & $12 \pm 7$ & $<0.001$ \\
\hline \multicolumn{5}{|l|}{ Days without organ support } \\
\hline Days without mechanical ventilation & $5 \pm 5$ & $5 \pm 6$ & $4 \pm 4$ & 0.59 \\
\hline Days without vasopressors & $13 \pm 8$ & $13 \pm 8$ & $12 \pm 7$ & 0.19 \\
\hline Days without renal replacement therapy & $24 \pm 10$ & $14 \pm 10$ & $15 \pm 8$ & 0.70 \\
\hline \multicolumn{5}{|l|}{ Type of infection (\%) } \\
\hline Gram-positive bacteria & 83 & 84 & 80 & 0.31 \\
\hline Gram-negative bacteria & 69 & 69 & 71 & 0.66 \\
\hline Fungal infection & 54 & 62 & 35 & $<0.001$ \\
\hline Viral infection & 11 & 12 & 10 & 0.58 \\
\hline
\end{tabular}

Italic indicates significance of $P$ values $(P<0.05)$ 
and 90-day mortality in surgical ICU patients with sepsis. The main finding of the study was that the transfusion of stored allogenic RBCs in a timeframe of 28 days before and after the beginning of sepsis was associated with a significantly higher 90 -day mortality risk. This association remained significant after adjustment for confounders.

A causal relationship underlying the higher mortality rate observed in the transfusion group cannot be undisputedly determined from these data. It might be explained by anaemia itself or alternatively by numerous mechanisms by which stored allogenic erythrocytes detrimentally effect homeostasis. Some of these mechanisms, such as impaired rheological properties, reduced oxygen release or the procoagulant effects of $\mathrm{RBC}$ derived microparticles [18-21, 30], develop immediately. Other unfavourable phenomena, particularly transfusion-related immunomodulation (TRIM), evolve over a prolonged period [31]. The mechanisms involved in TRIM are not completely understood, but modulation of cellular immunity is suggested to play a key role [32]. The observation that transfusion decreases the probability of rejection of cardiac and renal allografts [33-35] also supports the hypothesis that stored blood cells exert a lasting modulatory effect on immunity. The increase in the mortality gap between the transfusion and non-transfusion groups during the observation period noted in the present study might support the theory of a probable dominance of some immunological mechanisms responsible for poorer outcomes. The presence of complex immunomodulation associated with RBC transfusion in our patients is also supported by the significantly higher prevalence of positive fungal cultures in the transfusion group.

Septic patients requiring an RBC transfusion showed a more severe presentation of the disease. Upon enrolment, SOFA and APACHE II scores were significantly higher in the transfusion group, and these patients required more vasopressors and renal replacement therapy on day 1 . During the observation period, average SOFA scores remained significantly higher in patients who received allogenic RBCs. All SOFA subscores, with the exception of the SOFA-Central nervous system score, were higher in this group.

We also investigated the association between RBC transfusions and pre-existing medical conditions. Patients who received an allogenic blood transfusion were significantly more likely to have some type of malignant tumour in their medical history than patients in the non-transfusion group. This finding is consistent with the observation that anaemia is indeed very common in patients with malignant tumours [36].

\section{Conclusions}

Apart from the mentioned limitations, our findings imply that anaemia requiring the transfusion of stored RBCs in patients with sepsis is associated with higher 90-day mortality rates and disease severity. Further research is needed to determine causal relations.

\section{Limitations}

This observational study has some limitations that need to be highlighted. In our study, we focused on the general surgical ICU population with sepsis; therefore, our results may not be completely applicable to other ICU cohorts. Furthermore, the haemoglobin concentration before the transfusion was not recorded; thus, we were not able to determine whether patients were transfused according to a restrictive or liberal strategy. However, according to the standard operating procedures of our ICUs, patients rarely receive an RBC transfusion if they have a haemoglobin concentration greater than $8 \mathrm{~g} / \mathrm{dL}$. Although we observed significant associations between $\mathrm{RBC}$ transfusion and sepsis-related mortality and disease severity, our findings do not reveal the causal and biological relations of these observed associations. We postulated that the RBC transfusion exerted a detrimental effect on sepsis outcomes and severity, and patients with a more severe case of sepsis and concomitant anaemia might receive $\mathrm{RBC}$ transfusions more frequently. The biological mechanisms underlying our findings must be investigated in further studies.

\section{Additional file}

Additional file 1: Table S1. Multivariate Cox regression analysis regarding 90-day survival.

\section{Abbreviations}

APACHE: acute physiology and chronic health evaluation; ICU: intensive care unit; NYHA: New York Heart Association; RBC: red blood cell; SIRS: systemic inflammatory response syndrome; SOFA: sequential organ failure assessment; TRIM: transfusion-related immunomodulation.

\section{Authors' contributions}

All authors contributed to the study design, data acquisition, and data analyses and interpretation. Specifically, AG, BB and CM were involved in collecting the clinical data. AP, BS, MG and TB participated in the study design and clinical data monitoring or interpretation. TB contributed to the study design and conception, performed the bioinformatics analyses, and approved the statistical analyses. AG, AM, CM, IB, JH and KK designed the study, performed the statistical analyses, and drafted the manuscript. All authors were involved in either the drafting or revision of the manuscript. All authors read and approved the final manuscript.

\section{Author details}

${ }^{1}$ Department of Anesthesiology, University Medical Center, Georg August University, Goettingen, Germany. ${ }^{2}$ Department of Cardiac Surgery, University Hospital, Ruprecht Karls University, Heidelberg, Germany. ${ }^{3}$ Department 
of Thoracic and Cardiovascular Surgery, University Medical Center, Goethe University, Frankfurt, Germany. ${ }^{4}$ Department of General, Visceral and Pediatric Surgery, University Medical Center, Georg August University, Goettingen, Germany. ${ }^{5}$ Department of Medical Statistics, University Medical Center, Georg August University, Goettingen, Germany.

\section{Acknowledgements}

The authors thank the staff of the ICUs of the Department of Anesthesiology and Department of General and Visceral Surgery, all of whom were involved in patient care and monitoring.

\section{Competing interests}

The authors declare that they have no competing interests.

\section{Availability of data and materials}

The datasets used and analysed during the current study are available from the corresponding author upon reasonable request.

\section{Consent for publication}

Not applicable.

\section{Ethical approval and consent to participate}

This observational study was approved by the Institutional Ethics Committee of the University of Goettingen in Goettingen, Germany, and was performed in accordance with the provisions of the Declaration of Helsinki. The study was performed in accordance with relevant guidelines and regulations. The methods were performed in accordance with the approved guidelines. Written informed consent was obtained either from the patient or their legal representative.

\section{Funding}

This study was supported by the VolkswagenStiftung, Grant ZN3168. The funding body played no role in the study's design, data collection, analyses, and interpretation of data or writing of the manuscript.

\section{Publisher's Note}

Springer Nature remains neutral with regard to jurisdictional claims in published maps and institutional affiliations.

Received: 10 October 2018 Accepted: 5 December 2018 Published online: 11 December 2018

\section{References}

1. Angus DC, Linde-Zwirble WT, Lidicker J, Clermont G, Carcillo J, Pinsky MR. Epidemiology of severe sepsis in the United States: analysis of incidence, outcome, and associated costs of care. Crit Care Med. 2001;29:1303-10.

2. Ramachandran G. Gram-positive and Gram-negative bacterial toxins in sepsis. Virulence. 2014;5:213-8.

3. Schulte W, Bernhagen J, Bucala R. Cytokines in sepsis: potent immunoregulators and potential therapeutic targets - an updated view. Mediators Inflamm. 2013;20:13. https://doi.org/10.1155/2013/165974.

4. De Backer D, Orbegozo Cortes D, Donadello K, Vincent J-L. Pathophysiology of microcirculatory dysfunction and the pathogenesis of septic shock. Virulence. 2014;5:73-9.

5. Charlton M, Sims M, Coats T, Thompson JP. The microcirculation and its measurement in sepsis. J Intens Care Soc. 2017;18:221-7.

6. Ince C. The microcirculation is the motor of sepsis. Crit Care. 2005;9(Suppl 4):S13-9.

7. Spronk PE, Zandstra DF, Ince C. Bench-to-bedside review: sepsis is a disease of the microcirculation. Crit Care. 2004;8:462-8.

8. Jansma G, de Lange F, Kingma WP, Vellinga NA, Koopmans M, Kuiper MA, et al. 'Sepsis-related anemia' is absent at hospital presentation; a retrospective cohort analysis. BMC Anesthesiol. 2015. https://doi.org/10.1186/ s12871-015-0035-7.

9. Muady GF, Bitterman H, Laor A, Vardi M, Urin V, Ghanem-Zoubi N. Hemoglobin levels and blood transfusion in patients with sepsis in Internal Medicine Departments. BMC Infect Dis. 2016. https://doi.org/10.1186/ s12879-016-1882-7.
10. Murthy T. Blood transfusion practices in sepsis. Indian J Anaesth. 2014;58:643-6.

11. Mazza BF, Freitas FGR, Barros MMO, Azevedo LCP, Machado FR. Blood transfusions in septic shock: is $7.0 \mathrm{~g} / \mathrm{dL}$ really the appropriate threshold? Rev Bras Ter Intensiva. 2015;27:36-43.

12. Rosland RG, Hagen MU, Haase N, Holst LB, Plambech M, Madsen KR, et al. Red blood cell transfusion in septic shock_clinical characteristics and outcome of unselected patients in a prospective, multicentre cohort. Scand J Trauma Resusc Emerg Med. 2014;22:14.

13. Rygård SL, Holst LB, Wetterslev J, Johansson PI, Perner A. Higher vs. lower haemoglobin threshold for transfusion in septic shock: subgroup analyses of the TRISS trial. Acta Anaesthesiol Scand. 2017;61:166-75.

14. Holst LB. Benefits and harms of red blood cell transfusions in patients with septic shock in the intensive care unit. Dan Med J. 2016;63:B5209.

15. Harvey AR, Basavaraju SV, Chung K-W, Kuehnert MJ. Transfusion-related adverse reactions reported to the National healthcare safety network hemovigilance module, United States, 2010 to 2012. Transfusion. 2015;55:709-18.

16. Blajchman MA. Transfusion immunomodulation or TRIM: what does it mean clinically? Hematology. 2005;10(Suppl 1):208-14.

17. Vamvakas EC, Blajchman MA. Transfusion-related immunomodulation (TRIM): an update. Blood Rev. 2007;21:327-48.

18. Nagababu E, Scott AV, Johnson DJ, Dwyer IM, Lipsitz JA, Barodka VM, et al. Oxidative stress and rheologic properties of stored red blood cells before and after transfusion to surgical patients. Transfusion. 2016;56:1101-11.

19. Frank SM, Abazyan B, Ono M, Hogue CW, Cohen DB, Berkowitz DE, et al. Decreased erythrocyte deformability after transfusion and the effects of erythrocyte storage duration. Anesth Analg. 2013;116:975-81.

20. Li Y, Xiong Y, Wang R, Tang F, Wang X. Blood banking-induced alteration of red blood cell oxygen release ability. Blood Transfus. 2016;14:238-44.

21. Said AS, Rogers SC, Doctor A. Physiologic impact of circulating RBC microparticles upon blood-vascular interactions. Front Physiol. 2018. https://doi.org/10.3389/fphys.2017.01120.

22. Rhodes A, Evans LE, Alhazzani W, Levy MM, Antonelli M, Ferrer R, et al. Surviving sepsis campaign: international guidelines for management of sepsis and septic shock: 2016. Intens Care Med. 2017;43:304-77.

23. ProCESS Investigators, Yealy DM, Kellum JA, Huang DT, Barnato AE, Weissfeld $L A$, et al. A randomized trial of protocol-based care for early septic shock. N Engl J Med. 2014;370:1683-93.

24. Park DW, Chun B-C, Kwon S-S, Yoon YK, Choi WS, Sohn JW, et al. Red blood cell transfusions are associated with lower mortality in patients with severe sepsis and septic shock: a propensity-matched analysis. Crit Care Med. 2012;40:3140-5.

25. Dupuis C, Sonneville R, Adrie C, Gros A, Darmon M, Bouadma L, et al. Impact of transfusion on patients with sepsis admitted in intensive care unit: a systematic review and meta-analysis. Ann Intens Care. 2017. https ://doi.org/10.1186/s13613-016-0226-5.

26. Mansur A, Steinau M, Popov AF, Ghadimi M, Beissbarth T, Bauer M, et al. Impact of statin therapy on mortality in patients with sepsis-associated acute respiratory distress syndrome (ARDS) depends on ARDS severity: a prospective observational cohort study. BMC Med. 2015. https://doi. org/10.1186/s12916-015-0368-6.

27. Hinz J, Büttner B, Kriesel F, Steinau M, Frederik Popov A, Ghadimi M, et al. The FER rs4957796 TT genotype is associated with unfavorable 90-day survival in Caucasian patients with severe ARDS due to pneumonia. Sci Rep. 2017. https://doi.org/10.1038/s41598-017-08540-7.

28. Mansur A, Hinz J, Hillebrecht B, Bergmann I, Popov AF, Ghadimi M, et al. Ninety-day survival rate of patients with sepsis relates to programmed cell death 1 genetic polymorphism rs11568821. J Investig Med. 2014;62:638-43.

29. Singer M, Deutschman CS, Seymour CW, Shankar-Hari M, Annane D, Bauer $M$, et al. The third international consensus definitions for sepsis and septic shock (Sepsis-3). JAMA. 2016;315:801.

30. Bouchard BA, Orfeo T, Keith HN, Lavoie EM, Gissel M, Fung M, et al. Microparticles formed during storage of red blood cell units support thrombin generation. J Trauma Acute Care Surg. 2018;84:598-605.

31. Vamvakas EC, Bordin JO, Blajchman MA. Immunomodulatory and proinflammatory effects of allogeneic blood transfusion. Rossi Princ Transfus Med. 2016. https://doi.org/10.1002/9781119013020.ch62.

32. Ueta H, Kitazawa Y, Sawanobori Y, Ueno T, Ueha S, Matsushima K, et al. Single blood transfusion induces the production of donor-specific 
alloantibodies and regulatory T cells mainly in the spleen. Int Immunol. 2018;30:53-67.

33. Fernández FG, Jaramillo A, Ewald G, Rogers J, Pasque MK, Mohanakumar T, et al. Blood transfusions decrease the incidence of acute rejection in cardiac allograft recipients. J Heart Lung Transplant. 2005;24(7 Suppl):S255-61.

34. Verghese P, Gillingham K, Matas A, Chinnakotla S, Chavers B. Post-transplant blood transfusions and pediatric renal allograft outcomes. Pediatr Transplant. 2016;20:939-45.
35. Chavers BM, Sullivan EK, Tejani A, Harmon WE. Pre-transplant blood transfusion and renal allograft outcome: a report of the North American pediatric renal transplant cooperative study. Pediatr Transplant. 1997;1:22-8.

36. Frenkel EP, Bick RL, Rutherford CJ. Anemia of malignancy. Hematol Oncol Clin North Am. 1996:10:861-73.
Ready to submit your research? Choose BMC and benefit from:

- fast, convenient online submission

- thorough peer review by experienced researchers in your field

- rapid publication on acceptance

- support for research data, including large and complex data types

- gold Open Access which fosters wider collaboration and increased citations

- maximum visibility for your research: over $100 \mathrm{M}$ website views per year

At BMC, research is always in progress.

Learn more biomedcentral.com/submissions 